
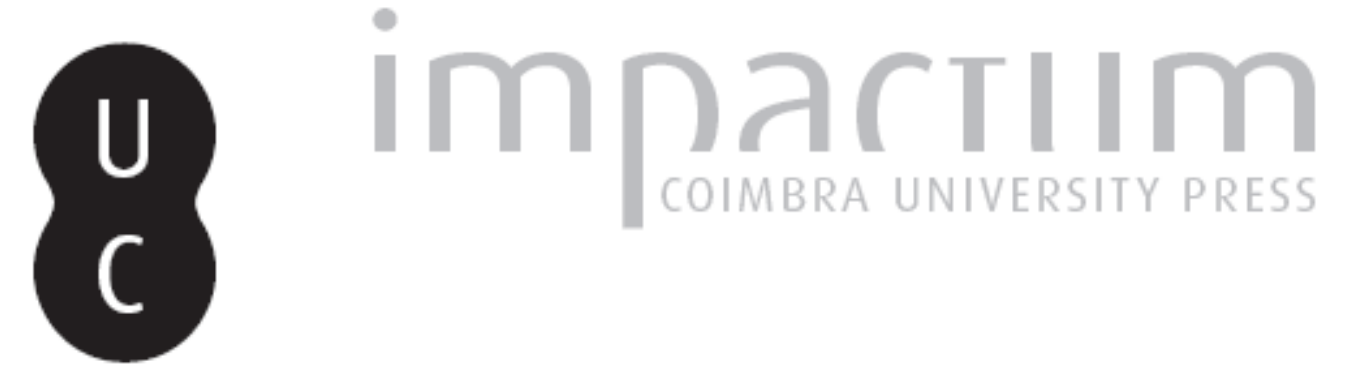

\title{
Pina Martins e a história do livro
}

\section{Autor(es): Anselmo, Artur}

Publicado por: Imprensa da Universidade de Coimbra

URL persistente:

URI:http://hdl.handle.net/10316.2/42560

DOI:

DOI:https://doi.org/10.14195/0870-8584_6_16

Accessed : $\quad$ 26-Apr-2023 13:29:06

A navegação consulta e descarregamento dos títulos inseridos nas Bibliotecas Digitais UC Digitalis, UC Pombalina e UC Impactum, pressupõem a aceitação plena e sem reservas dos Termos e Condições de Uso destas Bibliotecas Digitais, disponíveis em https://digitalis.uc.pt/pt-pt/termos.

Conforme exposto nos referidos Termos e Condições de Uso, o descarregamento de títulos de acesso restrito requer uma licença válida de autorização devendo o utilizador aceder ao(s) documento(s) a partir de um endereço de IP da instituição detentora da supramencionada licença.

Ao utilizador é apenas permitido o descarregamento para uso pessoal, pelo que o emprego do(s) título(s) descarregado(s) para outro fim, designadamente comercial, carece de autorização do respetivo autor ou editor da obra.

Na medida em que todas as obras da UC Digitalis se encontram protegidas pelo Código do Direito de Autor e Direitos Conexos e demais legislação aplicável, toda a cópia, parcial ou total, deste documento, nos casos em que é legalmente admitida, deverá conter ou fazer-se acompanhar por este aviso.

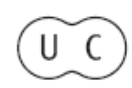




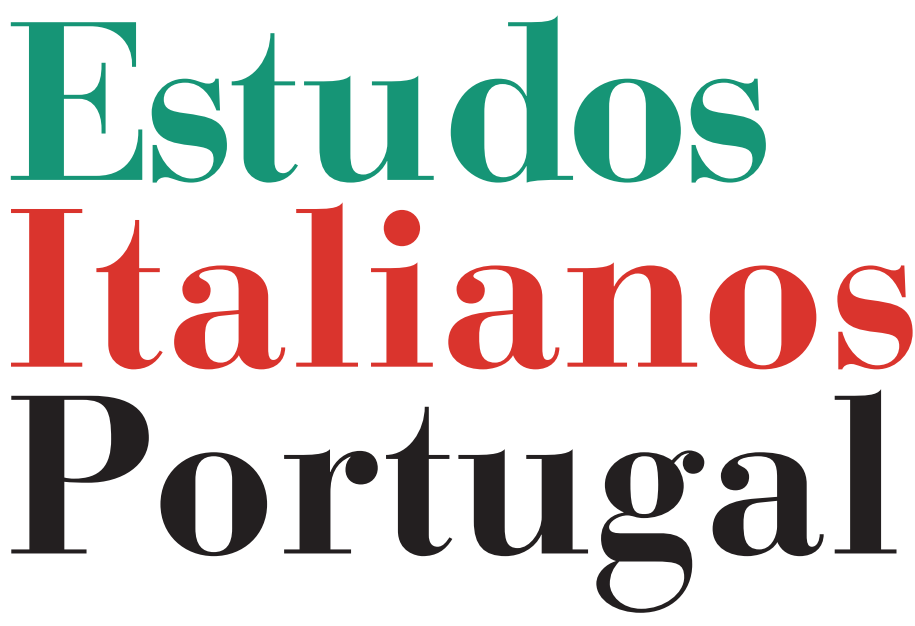

Instituto

Italiano

de Cultura

de Lisboa

Nova Série

$\mathrm{N}^{\circ} 6$ 


\section{PINA MARTINS E A HISTÓRIA DO LIVRO}

ARTur ANSELmo*

Uma visão globalizante dos problemas do livro, apta a captar não só os traços marcantes da sua individualidade exterior mas, principalmente, tudo o que nele é fermento de vida e de cultura, eis a linha orientadora daquilo que se tem convencionado chamar História do livro. Como projecto interdisciplinar autónomo, surgiu na Europa dos anos 50 graças ao magistério de Lucien Febvre, como realidade actuante e mobilizadora de energias provenientes de vários quadrantes geográficos, deu-lhe corpo Henri-Jean Martin, desde a publicação, em 1956, do clássico L’apparition du livre. Hoje, quando a História do livro deixou de ser, definitivamente, a terra incógnita de que falava Lucien Febvre no pós-guerra, centenas de obras da mais sólida investigação atestam, em diferentes países e a diferentes cadências, a vitalidade do tra-

*Professor universitário e estudioso da história do livro, área em que foi discípulo do Prof. Pina Martins. A sua tese de doutoramento, Origens da imprensa em Portugal (1991), obra de referência na matéria, foi apresentada na Sorbonne, que lhe concedeu o grau de Doutor em Estudos Portugueses. Antes do magistério universitário, dedicou-se à informação e ao jornalismo cultural (Director do semanário Observador), bem como à actividade editorial (Director literário da Editorial Verbo, coordenador da Enciclopédia luso-brasileira de cultura e da obra colectiva As grandes polémicas portuguesas). Foi presidente do Instituto Português do Livro e da Leitura, é membro da Academia Portuguesa de História e sócio efectivo da Academia das Ciências de Lisboa (Classe de Letras), onde dirige o Instituto de Lexicologia e Lexicografia. 
balho realizado. E, se alguma coisa importa lembrar neste momento, não será tanto a falta de contribuições monográficas sobre sectores habitualmente descurados (como a tipologia dos caracteres, o intercâmbio de gravuras e o itinerário do papel), que a seu tempo certamente sairão, mas a necessidade de, em caso algum, esquecermos a formação de base dos actuais e futuros historiadores do livro. Por outras palavras, em vez de se deixarem encantar pelas fantasias das chamadas hipóteses de trabalho, deverão os jovens investigadores cultivar sem descanso as humaniores littera, reaprendendo com humildade as lições dos eruditíssimos diplomatistas que os precederam. Porque - não tenhamos ilusões - toda a renovação passa, forçosamente, por um exame aprofundado da tradição diplomática dos textos originais e das fontes críticas.

Entre nós, poucos investigadores como Pina Martins estavam em melhores condições para sublinhar esta evidência. De facto, toda a sua obra de historiador do livro beneficiou largamente da excelente preparação cultural (humanística, em sentido lato) que recebeu e ampliou desde os bancos da Alma mater conimbricense. Chegado a Roma para leccionar, logo compreendeu que o destino lhe oferecia uma oportunidade invejável para multiplicar os seus conhecimentos biblio-iconográficos: assim, frequentou na Escola Biblioteconómica do Vaticano os cursos ministrados pelo Prof. Lamberto Donati e pôde então familiarizar-se com as questões suscitadas pelo livro ilustrado do Renascimento e do Barroco. Pela mesma altura, sob a orientação do Prof. Carlo Calcaterra, aprofundava em Bolonha os estudos de literatura italiana. Se aludo a estes dois mestres italianos, é porque sei quanto Pina Martins os admirava, ao ponto de frequentemente se lhes referir nos seus estudos.

Quando, em 1955, é transferido para a universidade francesa de Poitiers, dispõe já Pina Martins de uma sólida bagagem cultural e técnica, que lhe permitirá, a breve trecho, dar a lume as primeiras produções no domínio da investi- 
gação bibliográfica. Entretanto, à semelhança dos humanistas do Renascimento, para os quais o achamento de um manuscrito clássico desconhecido era um deleite para o espírito e uma festa para os sentidos, começara Pina Martins a constituir uma livraria particular de obras quatrocentistas e quinhentistas, núcleo inicial da Biblioteca de Estudos Humanísticos. Este admirável alfobre de instrumentos de trabalho, hoje propriedade do Banco Espírito Santo, foi a fonte de Castália da maior parte dos estudos de Pina Martins. Ajuntando com sacrifício pessoal verdadeiras preciosidades bibliográficas (adquiridas, na sua maior parte, em Itália, França e Portugal), não as fechava egoisticamente a sete chaves. Bem pelo contrário, a cada passo as mostrava em exposições bibliográficas franqueadas ao público, para as quais preparou excelentes catálogos.

Os primeiros trabalhos de Pina Martins no domínio da investigação bibliográfica são resultado das suas missões de serviço em Itália e França, como leitor em Roma e Poitiers: o Elogio della Bibliofilia (1957) e as Note su libri cinegètici italiani e francesi dei secoli XV e XVI (1958). Mas foi após o seu regresso temporário a Portugal, como assistente da Faculdade de Letras da Universidade de Lisboa, de 1961 a 1972, que surgiram os frutos sazonados dos anos de iniciação. Em 1965, quando o seu nome era já respeitado como autor de trabalhos acerca de Boccaccio, Dante, Pico della Mirandola, Frei António de Beja, Pascal e Luís António Verney, vemo-lo anunciar ao mundo culto, num artigo do Diário de Notícias, o aparecimento do Tratado de confissom, cimélio português impresso em Chaves, em Agosto de 1489, que o livreiro-antiquário Tarcísio Trindade tivera a fortuna de localizar numa miscelânea de livros antigos. Estupefactos, os estudiosos da paleotipografia viram ruir como um castelo de cartas a tese da prioridade alemã na introdução da imprensa cristã em Portugal. Os argumentos de Pina Martins eram de tal modo irrefutáveis que houve necessidade de se proceder a uma revisão sistemática dos conhecimentos sobre o assunto, 
os quais atribuíam a Johann Gherlinc a prioridade das impressões latinas em Portugal (Breuiarium bracharense, Braga, 1494) e a Valentim Fernandes e Nicolau de Saxónia a primazia das edições em português (Vita Christi, Lisboa, 1495). Doravante, sabia-se que um modesto tipógrafo anónimo imprimira em Chaves, seis anos antes da Vida de Cristo de Ludolfo Cartusiano, um livro em português. E o mais espantoso era que, desde 1489 até 1965 , em parte alguma se encontrava a mais leve referência ao incunábulo de Chaves, uma linha que fosse... Pudera Pina Martins ter-se limitado a dar a notícia, mas o seu avisado sentido das responsabilidades levá-lo-ia tão longe quanto possível, preparando com minúcia beneditina a edição diplomática e fac-similada do Tratado de confissom, a qual se publicaria em 1973, precedida de um estupendo estudo introdutório, sem dúvida uma das peças mais brilhantes que se produziram em todo o mundo acerca do livro português no século XV.

Em paralelo com este trabalho, delineou Pina Martins, em 1970, uma visão de conjunto acerca d'O Livro português no reinado de $D$. Manuel $I$, onde defende a ideia de que a produção bibliográfica portuguesa entre 1495 e 1521 é, sobretudo, um reflexo do que se passa na Europa do tempo. Aviso aos incautos: a importância dos livros religiosos em Portugal não é maior nem menor do que noutros países, e o predomínio da temática sagrada é acompanhado, entre nós, por uma crescente abertura ao profano, em obras que cobrem temas tão variados como a Medicina, a Oratória $\mathrm{Hu}$ manística, a Astronomia e a Astrologia, a Poesia, a Literatura de Viagens e até o doce e temperado feminismo do Espelho de Cristina. E se a lição dos textos merecia a Pina Martins um respeito escrupuloso, outro tanto poderia dizer-se a propósito das gravuras que ilustram os livros incunabulares e quinhentistas: num país onde escasseavam os estudos iconográficos, coube-lhe assumir, também aqui, um lugar pioneiro, como o provam o verbete "Livro português — iconografia", 
inserido em 1969 no Dicionário de literatura, dirigido por Jacinto do Prado Coelho, e, principalmente, o ensaio documentadíssimo e a tantos títulos inovador que intitulou Para a história da cultura portuguesa do Renascimento. A iconografia do livro impresso em Portugal no tempo de Dürer, cuja versão original apareceu em 1972.

Tendo partido para Paris nesse mesmo ano, a fim de assumir a direcção do Centro Cultural aí mantido pela Fundação Gulbenkian, impulsionou Pina Martins até 1983 (data do seu regresso definitivo a Portugal) numerosas iniciativas de carácter bibliográfico, na linha, aliás, da que promovera, ainda em Lisboa, por ocasião do quarto centenário da publicação d'Os Lusíadas. O catálogo da grande Exposição Camoniana de 1972, redigido com a sua habitual competência, deve-se-lhe por inteiro. É também camoniana - e de primeira água - a nota bibliográfica e crítica que escreveu de Paris, em 1973, para anteceder a reprodução fac-similada dos Autos e comédias portuguesas. Daí destaco este passo revelador das mais íntimas preocupaçōes científicas de Pina Martins:

O estudo rigoroso dos cimélios, a um nível de técnica bibliográfica, impõe-se decerto hoje em dia, sobretudo num país, como o nosso, onde escasseiam os bibliógrafos tecnicamente bem apetrechados. Mas o alargamento das análises temáticas a uma perspectiva de literatura comparada não se impõe menos em Portugal.

Dos numerosos trabalhos que Pina Martins redigiu e deu à estampa durante a sua permanência em Paris, no âmbito da História do livro, saliento, além dos estudos acerca de Erasmo e Thomas More, a introdução à edição fac-similada do Vincentius leuita et martyr de André de Resende, aparecida em 1981 sob protótipo de 1545 . Com exemplar autoridade, aí estuda Pina Martins, sucessivamente, os caracteres tipográficos do cimélio, a gravura da folha de rosto, a marca do impressor Luís Rodrigues e os problemas relacionados com o fabrico do papel. 
Após a sua volta definitiva a Lisboa, onde retomou, agora como professor catedrático, o convívio com colegas e discípulos da Faculdade de Letras, a extraordinária capacidade de trabalho deste grande investigador não abrandou. Prova disso, só nas áreas da Bibliografia e da História do livro, são, por exemplo, um estudo notável (em 1987) acerca do Modus curandi cum balsamo, livro de medicina editado por German Galharde cerca de 1530, assim como vários catálogos modelares, inventariando e descrevendo obras raras dos séculos XV e XVI existentes em bibliotecas portuguesas, com destaque para os que dedicou a Marsilio Ficino e Pico della Mirandola, não esquecendo os repertórios de incunábulos e livros quinhentistas da Academia das Ciências. Lugar não menos importante, nos anos 80 e 90 do século XX, ocupam as edições da Consolação às tribulações de Israel (Ferrara, 1553), de Samuel Usque, e da Menina e moça (Ferrara, 1554), de Bernardim Ribeiro, manifestações portentosas da vitalidade intelectual de Pina Martins, antes e depois da sua jubilação.

Também a biliofilia - ramo afim destes estudos - mereceu a Pina Martins algumas das páginas mais saborosas e bem humoradas que se publicaram em Portugal acerca do coleccionismo de espécies biblíacas no contexto do mercado livreiro europeu. Refiro-me, obviamente, a essa obra fascinante editada nos últimos dias de 2007, que leva o título de Histórias de livros para a História do livro, fruto de cerca de 60 anos de peregrinações (ou venationes librorum, como gosta de dizer o autor) em livrarias de Roma, Paris e Lisboa, principalmente. Não poucas vezes - sobretudo em Paris - o acompanhei nessas incursões, pelo que posso dar testemunho do respeito e da admiração que lhe votavam os melhores livreiros, alguns dos quais, avisados com antecedência da visita de Pina Martins às suas lojas, chegavam mesmo a preparar para ele exposiçóes de livros que sabiam interessar-lhe.

Termino lembrando que uma selecção dos melhores trabalhos de Pina Martins no domínio da História do livro se 
encontra no capítulo sétimo do seu opus magnum, isto é, na obra Humanisme et Renaissance de l'Italie au Portugal. Les deux regards de Janus, editada em Paris, sob os auspícios da École Pratique des Hautes Études, em 1989. “C'est peut-être là", escreve Pina Martins no prefácio desta obra, "que l'on peut trouver notre contribution la plus personnelle". Com efeito, tudo nesses trabalhos tem a marca da mais pura originalidade. Avesso à repetição de lugares-comuns e de banalidades, a obra do Prof. Pina Martins neste campo é a afirmação indesmentível de que a História do Livro, em Portugal, começou com ele. 